\title{
Benchmarking of Energy Time Series
}

\author{
M. A. Williamson
}

April 1990

Prepared for the

Energy Information Administration

U.S. Department of Energy

under Contract DE-AC06-76RLO 1830

Pacific Northwest Laboratory

Operated for the U.S. Department of Energy

by Battelle Memorial Institute 


\title{
DISCLAIMER
}

This report was prepared as an account of work sponsored by an agency of the United States Government. Neither the United States Government nor any agency thereof, nor Battelle Memorial Institute, nor any of their employees, makes any warranty, expressed or implied, or assumes any legal liability or responsibility for the accuracy, completeness, or usefulness of any information, apparatus, product, or process disclosed, or represents that its use would not intringe privately owned rights. Reference herein to any specific commercial product, process, or service by trade name, trademark, manufacturer, or otherwise, does not necessarily constitute or imply its endorsement, recommendation, or favoring by the United States Government of any agency thereof, or Battelle Memorial Institute. The views and opinions of authors expressed herein do not necessarily state or reflect those of the United States Government or any agency thereof.

\author{
PACIFIC NORTHWEST LABORATORY \\ operated by \\ BATTELLE MEMORIAL INSTITUTE \\ for the \\ UNITED STATES DEPARTMENT OF ENERGY \\ under Contract DE-ACO6-76RLO 1830
}

\begin{abstract}
Printed in the United. States of America
Available to DOE and DOE contractors from the

Office of Scientific and Technical Information, P.O. Box 62, Oak Ridge, TN 37831; prices available from (615) 576-8401. FTS 626-840t.

Available to the public from the National Technical Information Service, U.S. Department of Commerce, 5285 Port Royal Rd., Springfield, VA 2216 t.
\end{abstract}

NTIS Price Codes, Microfiche A01

Printed Copy

\begin{tabular}{cr}
\hline Price Code & Page Range \\
\hline A02 & $1-10$ \\
A03 & $11-50$ \\
A04 & $51-75$ \\
A05 & $76-100$ \\
A06 & $101-125$ \\
A07 & $126-150$ \\
A0B & $151-175$ \\
A09 & $176-200$ \\
A10 & $201-225$ \\
A17 & $226-250$ \\
A12 & $251-275$ \\
A13 & $276-300$ \\
A14 & $301-325$
\end{tabular}

\begin{tabular}{cc}
\hline Price Code & Page Range \\
\hline A15 & $326-350$ \\
A16 & $351-375$ \\
A17 & $376-400$ \\
A18 & $401-425$ \\
A19 & $426-450$ \\
A20 & $451-475$ \\
A23 & $476-500$ \\
A22 & $501-525$ \\
A23 & $526-550$ \\
A24 & $551-575$ \\
A25 & $576-600$ \\
A99 & $601-U p$
\end{tabular}


PNL -7337

UC -950

BENCHMARKING OF ENERGY TIME SERIES

M. A. Williamson

Apri 11990

Prepared for the Energy Information Administration U.S. Oepartment of Energy under Contract DE-AC06-76RLO 1830

Pacific Northwest Laboratory Richland, washington 99352 


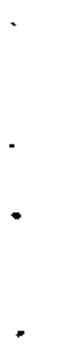

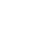




\section{EXECUTIVE SUMMARY}

Benchmarking consists of the adjustment of time series data from one source in order to achieve agreement with similar data from a second source. The data from the latter source are referred to as the benchmark(s), and often differ in that they are observed at a lower frequency, represent a higher level of temporal aggregation, and/or are considered to be of greater accuracy.

This report provides an extensive survey of benchmarking procedures which have appeared in the statistical literature, and reviews specific benchmarking procedures currently used by the Energy Information Administration (EIA).

The literature survey includes a technical sumnary of the major benchmarking methods and their statistical properties. Factors influencing the choice and application of particular techniques are described and the impact of benchmark accuracy is discussed.

EIA applications and procedures are reviewed and evaluated for residential natural gas deliveries series and coal production series. It is found that the current method of adjusting the natural gas series is consistent with the behavior of the series and the methods used in obtaining the initial data. As a result, no change is recommended. For the coal production series, a staged approach based on a first differencing technique is recomnended over the current procedure. A comparison of the adjustments produced by the two methods is made for the 1987 Indiana coal production series. 

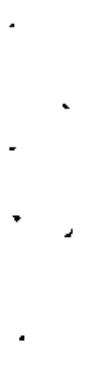


\section{CONTENTS}

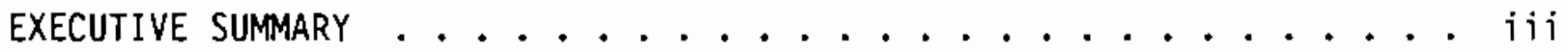

1.0 SUMMARY OF BENCHMARKING METHODS AND PROPERTIES ........ 1

1.1 QUADRATIC LOSS FUNCTION (QLF) BENCHMARKING . . . . . . . 2

1.2 MODEL-BASED BENCHMARKING . . . . . . . . . . . 10

1.3 GENERALIZED LEAST SQUARES (GLS) BENCHMARKING . . . . . . 12

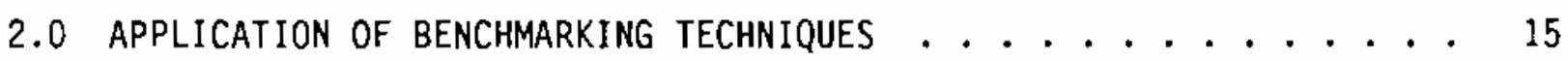

2.1 CONSIDERATIONS IN APPLYING MODEL-BASED BENCHMARKING .... 15

2.2 CONSIDERATIONS IN APPLYING QLF BENCHMARKING ....... 16

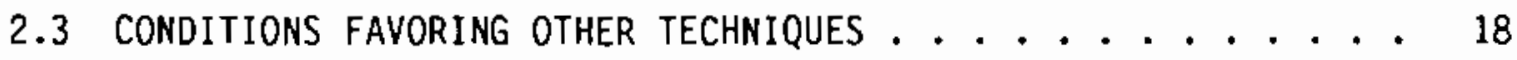

2.4 BENCHMARK ACCURACY ..................... 19

3.0 REVIEW OF EIA APPLICATIONS AND PROCEDURES . . . . . . . . . 21

3.1 RESIDENTIAL NATURAL GAS DELIVERIES APPLICATION . . . . . . 21

3.2 COAL PRODUCTION APPLICATION . . . . . . . . . 26

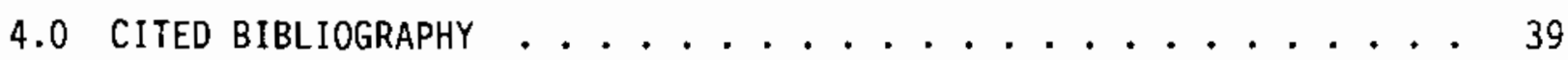

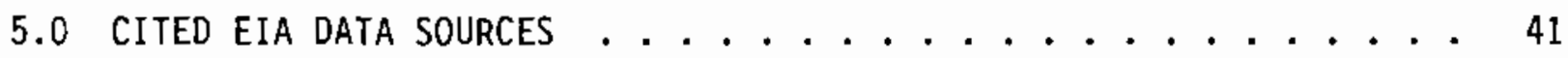

6.0 SUPPLEMENTARY BIBLIOGRAPHY ................. 43 


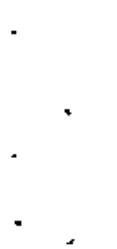




\section{FIGURES}

1. Comparison of QLF Adjustment Techniques .......... 5

2. Virginia Residential Natural Gas Deliveries, 1984-1987 . . . . 25

3. Relative ADjustments $(\mathbf{x}-\mathbf{z}) / \mathbf{z}$ in Virginia Residential Natural Gas Series, 1984-1987 (GLS Technique) ........ 27

4. Additive Adjustments $x-z$ to 1987 Indiana Coal Production . . . . 37

5. Relative Adjustments $(x-z) / z$ to 1987 Indiana Coal Production ................... . . 38

\section{TABLES}

1. Adjustment of Initial Quarterly Benchmarks to Annual Total (1987 Indiana Coal Production in Short Tons) ........ 34 


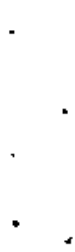




\subsection{SUMMARY OF BENCHMARKING METHODS AND PROPERTIES}

Benchmarking consists of the adjustment of time series data from one source in order to achieve agreement with similar data from a second source. The data from the latter source are referred to as the benchmark(s), and often differ in that they are observed at a lower frequency, represent a higher level of temporal aggregation and/or are considered to be of greater accuracy. For example, the EIA's monthly estimates of natural gas purchases and deliveries by state are based on survey samples. These estimates are later adjusted in order to agree with yearly totals based on an annual census of the sampled population. In this case, the monthly estimates are subject to sampling error, while the yearly totals are not; however, there may be other sources of error such as nonresponse, transcription errors, etc.

Two basic approaches to benchmarking have appeared in the literature. As originally conceived, the now most widely applied approach was empirical and data analytic in nature, utilizing few statistical properties of the underlying time series. In certain cases, subsequent work has identified conditions which provide a statistical basis for these techniques. The emphasis is on maintaining some empirically observed properties of the preadjusted series which are thought to be relatively unaffected by sampling error (e.g., month-to-month changes, seasonal patterns, etc.). The adjusted series is implicitly defined as that series which minimizes an appropriate quadratic loss function, subject to the benchmarking constraints. For example, the adjusted series might be defined as the one which best preserves (in the mean square error sense) the month-to-month differences of the unadjusted series and agrees with the yearly totals specified by the benchmark series. This will be referred to below as the quadratic loss function (QLF) approach. Principal proponents of QLF include Denton (1971), Helfand, Monsour and Trager (1977), Monsour and Trager (1979), Fernandez (1981), Cholette (1979, 1984), and Bozik and Otto (1988).

A second approach to benchmarking appeared in Hillmer and Trabeisi (1987). This approach is model-based and utilizes time series methods based upon the statistical properties of the pre-adjusted series and its survey 
errors. Benchmark errors are allowed as well. Adjustments are derived using standard Bayesian estimation techniques, together with related results by Scott and Smith (1974), Cleveland and Tiao (1976), Scott, Smith and Jones (1977), Hillmer and Tiao (1982), and Wolter (1985).

In a recent paper, Cholette and Dagum (1989) provided a partial unification of the QLF and model-based approaches under a generalized least squares (GLS)-like framework. This viewpoint has the advantage of shedding greater light on the statistical properties of the QLF approach and its relationship to the model-based approach, as well as allowing for extensions and combinations of the two methods.

\subsection{QUADRATIC LOSS FUNCTION (QLF) BENCHMARKING}

The Denton (1971) Approach

The basis for the quadratic loss function (QLF) approach to benchmarking was set forth by Denton (1971). He formulated the problem and provided a general solution for the adjustment of a monthly or quarterly series to conform to benchmarks for one or more years. Except in the case of simple level adjustment (see below), he was able to avoid the introduction of artificial discontinuities between the last period of one year and the first period of the next, a problem which had plagued earlier procedures.

Assuming $k$ intra-annual time periods per year over a span of $m$ years, denote the unadjusted series by $z=\left[z_{1}, z_{2}, \ldots, z_{n}\right]^{\prime}$, where $n=m k$. The benchmarks take the form of $m$ annual totals over $k$ consecutive time periods represented by $\mathbf{y}=\left[y_{1}, y_{2}, \ldots, y_{m}\right] '$. The problen is to adjust the vector $z$ to obtain a new vector $x=\left[x_{1}, x_{2}, \ldots, x_{n}\right]^{\prime}$ which minimally distorts $z$ while satisfying benchmark constraints. The distortion is measured by a quadratic penalty or objective function of the form $p(x, z)=(\mathbf{x}-\mathbf{z})^{\prime} A(\mathbf{x}-\mathbf{z})$, where $A$ is a suitable $n x n$ symmetric nonsingular matrix. Examples of appropriate specifications for the matrix $A$ are provided below. The benchmark constraints are of the form $y=B^{\prime} x$, where $B$ is the $n x m$ matrix 


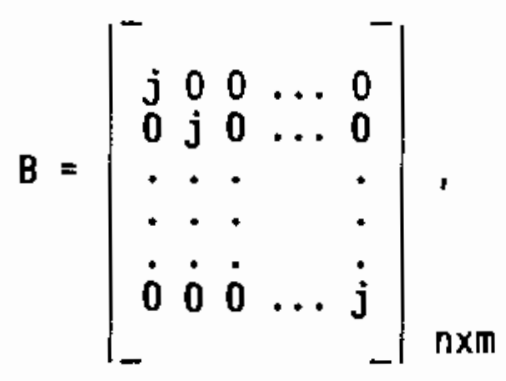

$\mathrm{j}$ denotes a $k \times 1$ vector of 1 's, and 0 denotes a $k \times 1$ vector of $0^{\prime} s$. Under this formulation, a solution of the form $x=z+C r$ is obtained using Lagrangian techniques, where $C_{n x k}=A-1 B\left(B^{\prime} A^{-1} B\right)^{-1}$ and $r=y-B^{\prime} z$ is the vector of discrepancies between the two sets of annual totals.

The simplest penalty functions allowed under the Denton (1971) formulation include the sum of squares of $k$ th differences for $k=0,1, \ldots$. For example, $k=0$ (level adjustment) denotes simple differences of the form $\left(z_{t}-x_{t}\right), k=1$ (first difference adjustment) denotes $\left[\left(z_{t}-z_{t-1}\right)-\left(x_{t}-x_{t-1}\right)\right]$, and so on. Level adjustment attempts to match the month by month levels of the observed and adjusted series as closely as possible, while satisfying the benchmarking constraint $y=B^{\prime} x$. Difference adjustment attempts to match the kth differences as closely as possible, while satisfying the benchmarking constraint.

To illustrate construction of the matrix $A$, the vector of first differences can be written as $D(z-x)$, where

$$
D=\left|\begin{array}{rrrrrrr}
1 & 0 & 0 & 0 & \ldots & 0 & 0 \\
-1 & 1 & 0 & 0 & \ldots & 0 & 0 \\
0 & -1 & 1 & 0 & \ldots & 0 & 0 \\
. & . & . & . & & . & . \\
\vdots & \vdots & . & . & & \vdots & \vdots \\
0 & 0 & 0 & 0 & \ldots & -i & 1
\end{array}\right|_{n \times n}
$$

The matrix $A_{k}$ corresponding to $k$ th differencing is given by $A_{k}=\left(D^{\prime}\right) k(D) k$, with $A_{0}=I_{n \times n}$. 
Alternative specifications include the sum of squares of the $k$ th proportional differences, where $k=0$ denotes $\left(z_{t}-x_{t}\right) / z_{t}$, and so on. In proportional adjustment, $A_{k}=W\left(D^{\prime}\right) k(D) k W$, where $H$ is an $n x n$ diagonal matrix with diagonal elements $w_{i j}=z_{i}-1$.

When $k>0$, differencing extends beyond the limits of the original series. Denton (1971) suggested setting $x_{t}=z_{t}$ for $t<1$ or $t>n$. For $t<1$, this results in the inclusion of the term $\left(z_{1}-x_{1}\right)^{2}$ in the penalty function; thus, minimization of the penalty function seeks to match the original and adjusted series at the first observation. For $t>n$, a similar situation occurs at the last observation.

\section{Statistical Justification of Denton's Approach}

Although Denton's methods were conceived as empirical solutions to the benchmarking problem, Fernandez (1981) showed that certain results are justified statistically under appropriate assumptions. For example, under the mode $1 \mathbf{z}=\mathbf{n}+\mathbf{e}$, where $\mathbf{z}$ is the observed series, $\boldsymbol{n}$ is the unobserved "true" series, and $e$ is a random vector with iid components having mean 0 and common variance, level adjustment yields best linear unbiased estimates for $n$. If the components et of e follow the random walk model et $=e_{t-1}+a_{t}$, where the at's are serially independent with mean 0 and common variance and initial condition $v_{0}=0$, the first difference adjustment is best linear unbiased for $n$.

The Cholette (1979) Approach

Cholette (1979) considered the effect of dropping terms involving $t<1$ or $t>n$ from the Denton (1971) penalty functions. He noted that Denton's approach specifies "initial conditions" which may result in spurious fluctuations in the adjustment series $\left(x_{t}-z_{t}\right)$ and hence does not optimally preserve the behavior of the original series.

The practical differences between the Denton and Cholette approaches are illustrated in Figure 1, which was taken from Cholette (1979). Monthly adjustments corresponding to Denton's first difference method and Cholette's first and second difference methods are plotted above their corresponding months for a four year series. To illustrate the relationship between the 


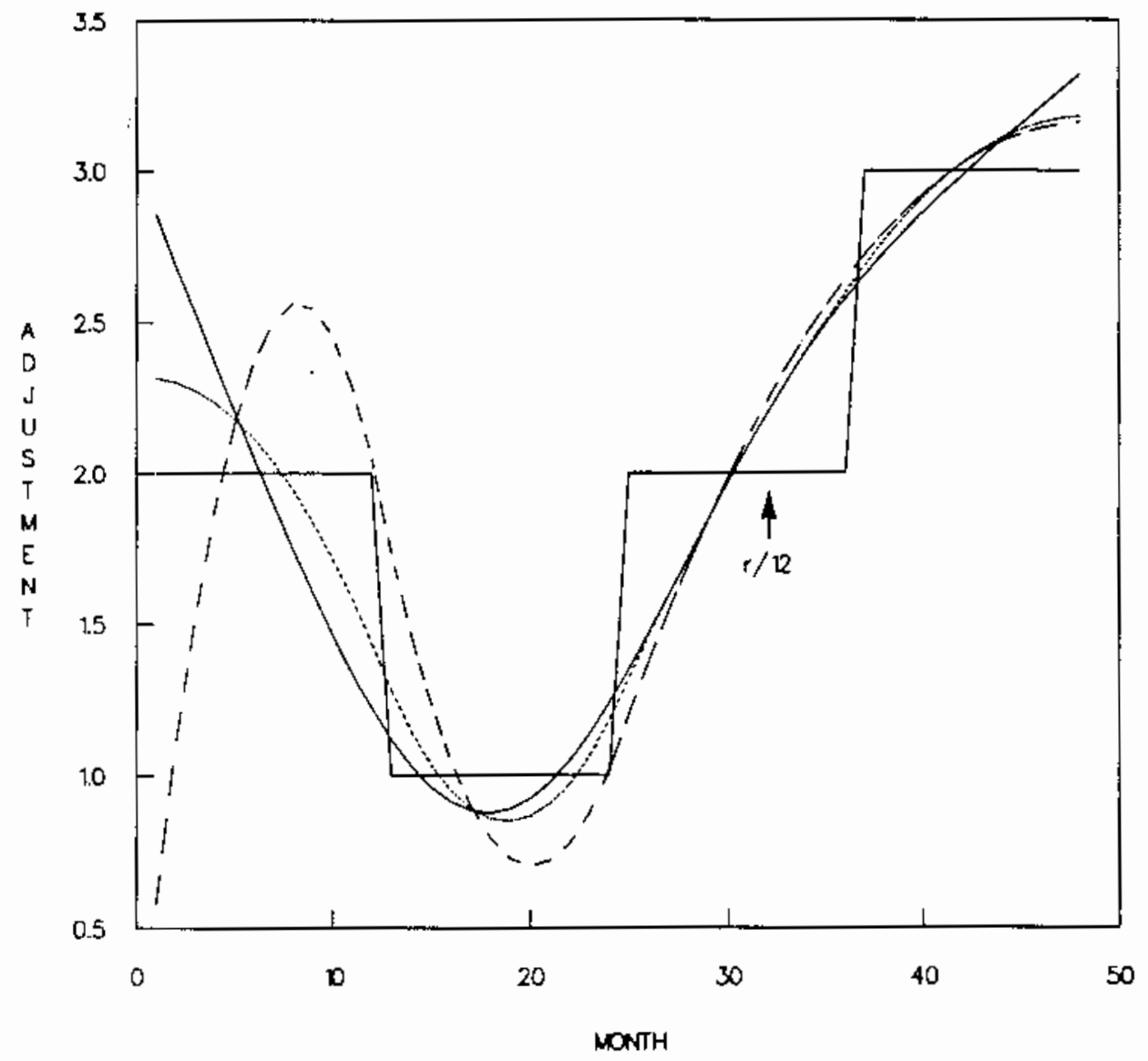

FIGURE 1. Comparison of QLF Adjustment Techniques. Monthly adjustments $x-z$ corresponding to Denton's first difference (- - - ), Cholette's first difference $(\cdots \cdots \cdots)$, and Cholette's second difference (-) techniques. From Cholette (1979).

monthly adjustments and the annual discrepancies, a step function related to the annual discrepancies is also plotted. The height of the step above the months for year $i$ represents the average monthly discrepancy $r_{j} / 12$. Note that the three methods tend to interpolate among the annual discrepancies and show close agreement during the middle years. The major differences appear in the adjustments made at the beginning of the first benchmarked year and the end of the final year. Adjustments based on first differences "level off" and tend toward uniformity during those periods, while adjustments based on second differences continue on a nearly linear trend. The impact of 
Denton's initial conditions assumptions appears as a marked peak in the first year's adjustments.

Cholette noted that the adjustments under his first and second difference methods are functions of the discrepancies and otherwise do not involve the individual $z j^{\prime} s$. This statement holds whenever $A$ does not involve the $z^{\prime}$ 's, and hence applies to the work of Denton (1971) as well. Cholette (1979) also noted that applying first differences to a single year results in uniform adjustments.

Unlike difference adjustment, first proportional difference adjustment results in adjustments which are functions of the $2 t$ 's. Applied to a single year, the technique results in a prorating of the annual discrepancy according to the relative magnitudes of the $\mathrm{zt}^{\prime} \mathrm{s}$. For multiple year applications, the previous interpretation of Figure 1 is still valid if the height of the ith step is redefined to be the proportional discrepancy for year $i,\left(\mathbf{B}^{\prime} \mathbf{x}\right)_{i} /\left(\mathbf{B}^{\prime} \mathbf{z}\right)_{i}$, and the proportional adjustments $x_{j} / z_{j}$ are plotted instead of the absolute adjustments $x_{i}-z_{i}$. Thus the proportional adjustment made in any month is an interpolation between the overall annual proportional discrepancies.

With respect to implementation of his benchmarking techniques, Cholette made several suggestions. He warned against their application to previously benchmarked series. Revisions are to be applied only to the raw series $z$ and $y$, since benchmarking a series containing previously benchmarked observations may result in artificially induced seasonality. He suggested a five year moving average implementation in which in which the central year represents final revisions and noted that a three year implementation is also possible, although "obviously" less reliable. Under the five year implementation, a series $z$ representing five years of raw subannual data is benchmarked using an annual (benchmark) series y covering the same time span. Data for a particular year receive their first revision when appearing as the most recent year in $z$. A second revision is made a year later, and the final revision is made as when the year appears as the central year in $\mathbf{z}$. Each revision is based entirely on raw data and does not involve the previous revisions. 
When choosing between the first and second difference techniques, Cholette preferred the first difference method, which he argued yields more conservative adjustments in the initial and final years. Finally, noting that proportional difference techniques enjoy wider application, Cholette recommended their use in the presence of marked seasonality, but preferred the use of nonproportional differencing otherwise.

Implementation of the Cholette Approach

Implementation of Cholette's approach requires more general computational techniques than those employed by Denton (1971). When using first difference adjustment, the matrix $D$ defined previously is modified by removing the first row. This results in the singularity of the matrix $A=D^{\prime} D$, so that Denton's formula for $C$ no ionger applies. Instead, $C$ is obtained from minimizing the augmented Lagrangian objective function $F(x, g)=(x-z)^{\prime} A(x-z)-2 g^{\prime}\left(y-B^{\prime} x\right)$. The minimizing vector is given by $\left(x^{*^{\prime}}, g^{*^{\prime}}\right)^{\prime}=H\left(z^{\prime}, r^{\prime}\right)^{\prime}$, where

$$
H(n+m) \times(n+m)=\left|\begin{array}{cc}
A & B^{-} \\
B^{\prime} & 0
\end{array}\right|^{-1}\left|\begin{array}{cc}
A & 0^{-} \\
B^{\prime} & I_{-}
\end{array}\right|^{-} .
$$

The matrix $\mathbf{C}$ appears as the upper right nxk corner of $\mathbf{K}$. Alternative Penalty Functions and Constraints

Helfand et al. (1977) described the adjustment of a series in order to benchmark to revised annual census figures for two particular years and link to (i.e., force agreement with) a more recent series at a particular month. The desired linking was introduced as an additional constraint. (When Lagrangian techniques yield a closed form solution, linking can be incorporated into the benchmarking constraints $y=B^{\prime} \mathbf{x}$ described on page 4 by adding an additional benchmark to $y$ and a corresponding column vector to B.) The intention was to keep changes in month-to-month trends, defined as the ratios $\left(z_{t} / z_{t+1}\right)$, to a minimum. Trends were to be preserved because they were thought to be aspects of the series little affected by sampling error 
(as compared, for example, to monthly levels). The authors preferred a penalty function of the form:

(forward trend revision)

$$
\begin{aligned}
p_{0}(x, z)=w_{0} w_{0}, \text { where } w_{0} & =\left(\left(w_{0}\right) 1_{1},\left(w_{0}\right)_{2}, \ldots,\left(w_{0}\right)_{n-1}\right)^{\prime} \\
& \text { and }\left(w_{0}\right)_{i}=\left(z_{j} / z_{j}+1-x_{j} / x_{j}+1\right),
\end{aligned}
$$

to be minimized subject to the benchmark and linking constraints described above.

Unable to obtain a closed form solution corresponding to po, the authors considered three alternative penalty functions:

(logarithmic trend revision)

$$
p_{1}(x, z)=w_{1}{ }^{\prime} w_{1} \text {, where }\left(w_{1}\right) j=\left[\ln \left(z_{j} / z_{j}+1\right)-\ln \left(x_{j} / x_{i}+1\right)\right],
$$

(first difference revision)

$$
P_{2}(x, z)=w_{2} w_{2} \text {, where }\left(w_{2}\right) i=\left[\left(z_{j}+1-z_{j}\right)-\left(x_{i}+1-x_{j}\right)\right] \text {, and }
$$

(first proportional difference revision)

$$
P 3(x, z)=w_{3}{ }^{\prime} w_{3} \text {, where }\left(w_{3}\right) i=\left[\left(z_{i+1}-x_{j+1}\right) / z_{j+1}-\left(z_{i}-x_{j}\right) / z_{i}\right] \text {. }
$$

Functions $P_{2}$ and $P_{3}$ are simply the first difference and first proportional difference penalty functions discussed above. Function $\mathrm{pl}$ was chosen by the authors because of its similarity to $\mathrm{po}$, and because numerical solution was tractable.

The authors compared the revised series resulting from each approach to the corresponding original series on the basis of month-to-month and year-toyear trends. Ratios of, and differences between, the individual subannual estimates ( $x t^{\prime} s$ and $z t^{\prime} s$ ) were also examined. In addition, the average of the squared differences in trends, $\left(x_{t+1} / x_{t}-z_{t+1} / z_{t}\right)^{2}$, was formed for each pair of original and updated series. Based on these comparisons, $\mathrm{P} 3$ was judged to be the preferable approach, and it was noted that little improvement could 
be expected from $p_{0}$, since the average squared difference in trends for $P_{3}$ was quite small.

Monsour and Trager (1979) revisited the above penalty functions. In the application discussed, the functions were minimized subject to a single yearly benchmark and a single link value (i.e., monthly benchmark). Again, PO was considered to be the ideal penalty function, since it attempts to retain relatively stable aspects of the series (i.e., month-to-month trends and seasonality), but was not used because the minimization problem could not be solved in closed form. The authors also noted, however, that revisions based on 13 provided a good approximation to those which would be obtained from $p_{0}$, since $(i) p_{3}=0$ implies $p_{0}=0$, and $(i i)$ upon substitution of the minimizing $x_{i}{ }^{\prime} s$, the mean of the $\left[\left(w_{3}\right)_{j}\right]^{2}$ terms was less than $10^{-6}$. Since the reported $x$ was rounded to integers, it was argued that any additional accuracy gained from using po would likely be lost.

In discussing problems inherent in their methodology, Monsour and Trager noted that the techniques will tend to preserve any artificial seasonality introduced by the survey design and estimation procedures (e.g., rotating panels). No suggestions were offered for dealing with this problem.

Bozik and 0tto (1988) also studied options for benchmarking monthly retail time series to annual surveys or censuses. The methods compared were first proportional difference revision (using penalty function $\mathrm{p}_{3}$ ), the solution to which was claimed to be a close approximation to the solution for backward trend revision (using penalty function $p_{0}$ 'with subscript $i+1$ replaced by $i-1$ ), and a function suggested by Laniel (1986) for minimizing relative month-to-month changes defined by:

(backward relative trend revision)

$$
p_{4}(x, z)=w_{4}{ }^{\prime} w_{4} \text {, where }\left(w_{4}\right) i=\left[\left(z j-1 x_{j}\right) /\left(z_{j} x_{j}-1\right)-1\right]
$$

Proportional difference revision and backward relative trend revision were compared based on their resulting absolute revisions $x_{t}-z t$, relative revisions $\left(x_{t}-z_{t}\right) / z_{t}$, month-to-month percent changes 
$100 *\left[\left(x_{t} / x_{t-1}\right)-\left(z_{t} / 2 t-1\right)\right]$, seasonally adjusted month-to-month percent changes, and percent changes in seasonal factors. Minima, maxima, means, medians, and standard errors of the above quantities were calculated for each method. These summary statistics provided empirical measures by which the various methods were compared. For example, the maximum absolute revision $\max _{t}\left\{x_{t}-z_{t}\right\}$ was computed for each method. For a given method, this quantity indicates the maximum deviation between the original and revised series. In making these comparisons, the authors found analys is of $\left(x_{t}-z_{t}\right) / z_{t}$ to be a particularly useful diagnostic tool for studying the effects of benchmarking on a series $z$. They also noted that study of the percentage differences between benchmarks and their corresponding sums of the original series provides a useful check on the precision of the series and its benchmarks. For the series studied, Bozik and otto found little difference in the revised series derived using the two methods, although substantially greater computational effort was encountered in using p4.

\subsection{MODEL-BASED BENCHMARKING}

Hillmer and Trabelsi (1987) proposed a model-based approach to benchmarking which takes into account the statistical properties of the benchmarks, the series being benchmarked, and the survey errors associated with that series. Since more details are provided in Section 1.3, where the technique is seen to be a special case of the more general generalized least squares (GLS) approach, only a brief description will be given here.

This benchmarking is based on the model

$$
\mathbf{z}=\mathbf{n}+\mathbf{e},
$$

where $z$ is the observed series which provides an initial estimate of the "true" series $n$, and e represents sampling error. It is assumed that $n$ follows an autoregressive integrated moving average (ARIMA) model

$$
\phi_{n}(B)\left(n_{t}-\mu\right)=\theta_{n}(B) w_{t} \text {. }
$$


and that e follows a mean zero autoregressive moving average (ARMA) model

$$
\phi_{\mathrm{e}}(B) e_{\mathrm{t}}=\theta_{\mathrm{e}}(B) a_{\mathrm{t}} .
$$

where $n$ and $e$ are mutually independent. In (1.2.2), $\phi_{n}(B)$ is a polynomial in the backshift operator $B$ with zeros on or outside the unit circle, $\theta_{n}(B)$ is a poiynomial with zeros outside the unit circle and different from the zeros of $\phi_{n}(B)$, and $w_{t}$ is white noise. The value of $\mu$ is $E\left(n_{t}\right)$, and is taken to be zero if $n_{t}$ is nonstationary. In $(1.2 .3), \phi_{e}(B)$ and $\theta_{e}(B)$ are polynomials with zeros outside the unit circle and at is white noise. From (1.2.1) the model for $z$ is

$$
\phi(B)\left(z_{t}-\mu\right)=\theta(B) b t \text {, }
$$

where $\phi(B)=\phi_{n}(B) \phi_{e}(B)$ and $\theta(B)$ may be derived from (1.2.2) and (1.2.3) using results of Hillmer and Tiao (1982). Scott and Smith (1974) and Scott, Smith, and Jones (1977) also described such models for time series based on sample surveys.

Benchmarking constraints are specified in the form

$$
y=B n+u,
$$

where $y$ is an observed $m \times 1$ vector, $B$ is an $m \times n$ matrix, and $u$ is an $m \times 1$ multivariate normal error vector with mean 0 and covariance $V_{U}$, independent of $n$ and $e$. The matrix $V_{u}$ may be null if $y$ is observed without error. Each row of the vector equation represents a benchmark constraint.

Under normality assumptions, the authors showed that the revised benchmarked series $x$ is the minimum mean squared error estimate of $\mathbf{n}$ given $\mathbf{z}$ and $y$; that is, $x=E(n \mid z, y)$. They gave formulas for $E(n \mid z, y)$ and $\operatorname{Cov}(n \mid z, y)$ (see Section 1.3) in terms of the parameters of the various processes, and showed that benchmarking improves the estimation of $\boldsymbol{n}$ in the sense of the well-known result that $\operatorname{Cov}(\mathbf{n} \mid \mathbf{z})-\operatorname{Cov}(\mathbf{n} \mid \mathbf{z}, \mathbf{y})$ is nonnegative definite. 


\subsection{GENERALIZED LEAST SQUARES (GLS) BENCHMARKING}

A formal unification of QLF and model-based benchmarking can be achieved through a generalized least squares (GLS) structure. Cholette and Dagum (1989) provided such a structure based on the following system of equations:

$$
\begin{array}{ll}
z=n+e, & E(e)=0, E\left(e e^{\prime}\right)=v_{e} \\
y=B n+u, & E(u)=0, E\left(u u^{\prime}\right)=v_{u} \\
P\left(n-y_{i}\right)=w_{1} & E(w)=0, E\left(w w^{\prime}\right)=v_{w}=\sigma_{w} 2 I \\
n=y_{r}+v_{1} & E(v)=0, E\left(w^{\prime}\right)=v_{v}
\end{array}
$$

In (i), $n$ denotes the true monthly values of the quantity of interest, $z$ denotes the observed time series, and $\mathbf{e}$ is usually interpreted as sampling error (but may also include errors due to frame deterioration over time, nonresponse, imputation, reporting errors, etc.). The matrix $V_{e}$ must usually be estimated from the unit-level data used to obtain z. Cholette and Dagum (1989) assumed $e$ followed an autoregressive process of the form,

$$
Q_{n \times n} e^{\prime}=a, E(a)=0, E\left(a^{\prime}\right)=\sigma_{a}^{2} I,
$$

where $n^{\prime} \leq n$, and $n$ denotes the length of the observed series $z$. When $Q^{\prime} Q$ is nonsingular, the covariance matrix for $e$ is $V_{e}=\sigma_{a^{2}}^{2}\left[Q^{\prime} Q\right]^{-1}$, with generalized inverse matrix $C_{e}:=V_{e}-1=\sigma_{a}^{2} I$. When $Q^{\prime} Q$ is singular, as is necessarily the case when $n^{\prime}<n$, it is still possible to write $C_{e}=\sigma_{a}-2$ $\left[Q^{\prime} Q\right]$.

The vector $y$ in ( $i i)$ denotes the vector of benchmarks observed with error u. When $y$ is derived from a census of the population of interest, it is often assumed that $V_{u}=0$, even though some error may still exist; e.g., reporting errors, transcription errors, etc. When the benchmarks are known to be subject to error, an estimate of $V_{u}$ must be obtained. The matrix $B$ allows for more general benchmarking constraints than previously considered. For example, a constraint of the form $x_{t}+x_{t+1}+\cdots+x_{t+j}=y$ can be specified by including a row in $B^{\prime}$ (the $i$ th, say) with $1^{\prime} s$ in the $t$ to $t+j$ th positions and 0 's 
elsewhere, and by setting $y_{j}=y$ in $y$. Note that a link point constraint is covered by the special case $x_{t}=y_{i}$.

In ( $i i i)$, the random vector $y_{i}$ represents intervention effects and $P$ is an $n^{\prime} \times n\left(n^{\prime} \leq n\right)$ autoregressive matrix operator defining an ARIMA model for $n$. Most benchmarking applications to date have assumed $y_{i}=0$. In general, $p$ and the constant $\sigma_{w^{2}}$ are unknown and must be estimated. Since $n$ is not observed, this estimation is generally nontrivial.

Equations (iv) allow for a stochastic or deterministic seasonal pattern $s$ by selecting $y_{r}=s$. The nature of this pattern is not typically known in advance and must therefore be estimated from available data. This is intended to be a substitute for ( $i i j)$, as ( $i i i)$ and (iv) are not typically used together. As in (i), the error vector $v$ is assumed to follow an autoregressive process of the form,

$$
G V=c, \quad E(c)=0, E\left(c c^{\prime}\right)=\sigma_{c^{2}} I .
$$

The above system of equations may be written as

$$
Y=X n+U, \quad E(U)=0, \quad E\left(U^{\prime}\right)=V
$$

where $Y^{\prime}=\left[z^{\prime}, y^{\prime},(P y i)^{\prime}, y r^{\prime}\right], \quad X^{\prime}=\left[I, B^{\prime}, P^{\prime}, I\right], U^{\prime}=\left[e^{\prime}, u^{\prime}, w^{\prime}, v^{\prime}\right]$,

and $v=\left|\begin{array}{cccc}-v_{e} & 0 & 0 & 0 \\ 0 & v_{u} & 0 & 0 \\ 0 & 0 & v_{w} & 0 \\ 0 & 0 & 0 & v_{V_{-}}\end{array}\right|$. If we define $v=C^{-1}=\left|\begin{array}{cccc}c_{e}-1 & 0 & 0 & 0 \\ 0 & c_{u}-1 & 0 & 0 \\ 0 & 0 & C_{W}-1 & 0 \\ 0 & 0 & 0 & C_{V}^{-1}\end{array}\right|$,

The GLS estimator $n^{*}=\left(X^{\prime} v-1 X\right)-1 x^{\prime} v^{-1} Y$ of $n$ and its covariance matrix $V\left(n^{*}\right)=\left(X^{\prime} V-1 X\right)-1$ may be written 


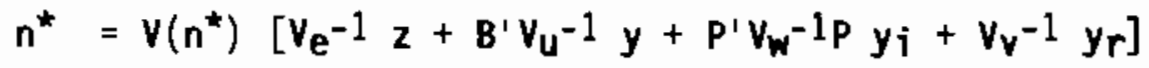

$$
\begin{aligned}
& =V\left(n^{*}\right)\left[C_{e} z+B^{\prime} C_{u} y+P^{\prime} C_{W} P y_{i}+C_{V} y_{r}\right] \text {, } \\
& V\left(n^{*}\right)=\left[V_{e}-1+B^{\prime} V_{u^{-1}}-1 B+P^{\prime} V_{w}-1 P+V_{v}-1\right]-1 \\
& =\left[C_{e}+B^{\prime} C_{u} B+P^{\prime} C_{W} P+C_{v}\right]-1 \text {. }
\end{aligned}
$$

Following Hillmer and Trabelsi (1987), a two step calculation for $\mathrm{n}^{\mathbf{*}}$ is to first compute the estimator $n_{0}^{*}$ for $n$, assuming no benchmarks, and then adjust for the benchmarks:

$$
\begin{aligned}
n_{0}^{*} & =\left[C_{e}+P^{\prime} C_{w} P+C_{v}\right]-1\left[C_{e} z+P^{\prime} C_{w} P y_{i}+C_{v} y_{r}\right] \\
& =V\left(n_{0}^{*}\right)\left[C_{e} z+P^{\prime} C_{w} P y_{i}+C_{v} y_{r}\right], \\
n^{*} & =n_{0}^{*}+V\left(n_{0}^{\star}\right) B^{\prime}\left[B V\left(n_{0}^{*}\right) B^{\prime}+V_{u}\right]^{-1}\left[y-B n_{0}^{\star}\right] .
\end{aligned}
$$

When feasible, the two step solution reduces computation and aids in the computation of $n^{*}$ when $v_{u}=0$.

When equation (iv) above is ignored and $V_{u}=\sigma_{U} 2 I$, and $y_{i}=0$, the GLS model parallels the Hillmer-Trabelsi model. When equations ( $i i i)$ and (iv) are ignored, $Q$ is taken to be $D$, the first difference operator defined on page 4 , and $V_{u}=0$, then the GLS model provides a statistical basis for the QLF model with penalty function equal to the sum of squares of first differences. The covariance matrix for the QLF estimates is obtained by letting $\sigma_{U^{2}}$ tend to 0 in $V\left(n^{\star}\right)$.

Formally, the QLF model with a first proportional difference penalty function can also be represented by the GLS model. But the matrix $C_{e}=\sigma_{a}-2 W D^{\prime} D W$, where $W$ and $D$ are defined as on page 4 , is a function of the data, violating the assumptions of a GLS model. 


\subsection{APPLICATION OF BENCHMARKING TECHNIQUES}

\subsection{CONSIOERATIONS IN APPLYING MODEL-BASED BENCHMARKING}

The statistical model-based approach is clearly preferable whenever appropriate and practicable. Unlike the QLF approach, the model-based approach accounts for the stochastic properties of the series being benchmarked, incorporates the effect of survey errors, and allows for errors in the benchmarks themselves. Hillmer and Trabelsi (1987) showed that the revised estimates derived from the model-based approach have smaller mean square error than the prebenchmark estimates. Furthermore, this mean square error can be estimated.

The chief disadvantages of the model-based approach are the substantial data retention (on the order of five years) required, the required estimation of models for the observed series $z t$ and sampling error $e t$, and the delay of at least two years in obtaining "final" revisions. In order to model the series et, estimates of the variances and autocovariances of the et must be obtained. This necessitates the retention of unit-level data for a number of months. The exact number of months required would depend on the sample rotation scheme, the number of lagged covariances deemed important, etc. Hillmer and Trabelsi (1987), for example, showed how results of Cleveland and Tiao (1976) can be applied to estimate the $i, j$ th element of $V\left(n 0^{\star}\right)$, the covariance matrix of the estimator $n^{*}$ for $n$ assuming no benchmarks, when $i$ and $j$ are not too near the ends of the series $z$. They provided an example wherein five years of data were used to benchmark a single central year. This imposed a two year delay in obtaining "final" revisions after the yearly benchmark became available for the target year.

Cholette and Dagum (1989) pointed out that a pure ARIMA model does not allow for deterministic or other exogenous effects such as those incorporated into equations ( $i j i)$-(iv) of the GLS approach. They also noted that e may embody more than sampling error, including errors due to an obsolete frame, non-response, imputation, reporting errors, etc. In the case of the EIA's monthly figures for residential natural gas purchases and deliveries, for example, sample totals are inflated based on a previous year's totals; thus, 
a systematic bias may be introduced for a given year. In its present form, the Hillmer-Trabelsi model cannot account for such errors.

Finally, it should be noted that the model-based approach is heavily dependent upon identifying a suitable ARMA model for $\mathbf{e}$, a representation which may not be appropriate in all situations. In the case of the EIA's residential natural gas series, monthly estimates for a given year are based on a single sample of establishments, while the samples for different years are drawn independently. Thus monthly sampling errors within a calendar year are correlated, while errors between years are uncorrelated, resulting in an error structure not well represented by an ARMA model.

\subsection{CONSIDERATIONS IN APPLYING QLF BENCHMARKING}

Several conditions favor the use of the QLF over the model-based approach. These include:

1. Sufficient data and/or expertise are not available for modeling et and/or $z t$.

2. Revised monthly estimates are required soon after obtaining the corresponding benchmark.

3. An easily mechanized benchmarking process is required.

4. Identifiable stable aspects (e.g., stable monthly trends, $z t / z t+1$ ) are exhibited by unbenchmarked series.

5. $x_{t}>0$ is required for all $t$.

As indicated above, the data requirements for implementing the model-based approach to benchmarking are rather extensive. By contrast, the amount of data required for implementation of the QLF approach is relatively small. If smooth transitions are required between benchmarking periods (e.g., successive years), as little as three years' data on $z$ will suffice. If yearly transitions are not a concern, each benchmark period can be revised separately. In neither case are data related to e required (a)though implicit assumptions are made in applying the technique).

The price one pays for the less stringent data requirements of the QLF approach is not insignificant, however. Except for the special cases 
considered by Fernandez (1981), the statistical properties of the revisions obtained are still not well understood. Even when the statistical properties are known, the assumptions upon which they are based are not of sufficient generality to suffice for most applications. The QLF techniques are therefore best regarded as numerical adjustment techniques.

For those penalty functions and constraints leading to a closed form solution, QLF benchmarking is more easily mechanized than the model-based approach. Under the model-based approach, modeling of the time series $z$ requires the usual identification stage, which may not be amenable to mechanization. Once this series has been modeled, additional judgment may be required in approximating the desired revisions. The judgment required in QLF benchmarking typically involves either

(i) identification of some aspect of the series which is sufficientiy stable to incorporate into the penalty function, or

(ii) assumptions regarding the manner in which the yearly discrepancies $r$ arise and should be distributed as adjustments to the subannual series.

As an example of (i), most census bureau applications described in the literature assume that the monthly trends $z_{t} / z_{t+1}$ are among the more accurate and stable aspects of the unbenchmarked series. Consequently, it is natural to attempt to preserve the same trends in the adjusted series by making use of a penalty function similar to $\mathrm{p0}$. In practice, functions similar to p3 are used instead, since they are mathematically more tractable and have been shown to yield similar results in typical applications.

Consideration of ( $i$ ) will aid in choosing between single and multiple year benchmarking, as well as between the proportional and nonproportional differencing techniques. Figure 1 illustrates that the application of the first and second difference techniques to a multiple year series results in adjustments which tend to interpolate among the annual discrepancies $r / 12$. (This is also clear from the formula $x=z+C r$.) This form of adjustment seems appropriate if one suspects that the sampling errors are correlated both within and between years. This is supported by the work of Fernandez (1981), who established that the first difference technique is statistically 
justified if the sampling errors are assumed to follow a random walk model. If, on the other hand, sampling errors are independent between years, it seems more appropriate to apply these techniques to a single year.

Regarding the choice between simple and proportional differencing, recall that Cholette (1979) preferred the use of simple differencing, except in the presence of marked seasonality, when he preferred proportional differencing. A second instance in which proportional techniques are likely to be more appropriate is when the year-to-year variability for a particular subannual period (e.g., month) appears to be an increasing function of level. This is the case in the EIA residential natural gas series, where variability is much greater during the high volume (colder) months than during the low volume (warmer) months. It is then appropriate to assign more of the annual discrepancy to the more variable months, as occurs in applying proportional techniques.

Finally, by using QLF proportional differencing, positive benchmarked values can often be guaranteed. Since highly seasonal series may exhibit certain months for which $n_{t}$ is near 0 , the other forms of benchmarking may result in $x_{t}<0$, which is clearly undesirable.

\subsection{CONDITIONS FAVORING OTHER TECHNIQUES}

Certain extensions and/or combinations of the QLF and model-based approaches can be accommodated under the GLS framework. Benchmark errors can be introduced into the QLF technique by taking $V_{u}$ nonzero in equation ( $i i$ ) of the GLS framework. Interventions can be incorporated into the model-based approach by taking $y_{i}$ nonzero in equation (iii). Auxiliary information related to $n$ (e.g., seasonal and/or trend components) can be included in the model-based approach through $\mathbf{y r}_{\mathbf{r}}$ in equation (iv).

Modification of equation ( $i$ ) to $z=b n+e$ is suggested by the work of Fernandez (1981). This modification may be useful in adjusting for certain forms of bias. 


\subsection{BENCHMARK ACCURACY}

In the many of the methods discussed above, it is assumed, either implicitly or explicitly, that the benchmark totals are unbiased estimates of the corresponding "true" totals. For the model-based or extended QLF approach, these benchmarks may be subject to error. Either approach is sufficiently flexible to cover the extreme cases in which (i) the benchmarks are observed without error, and ( $i i)$ the benchmarks are subject to error which may even be greater than that of the corresponding subannual totals.

Although the accuracy of the benchmark values is not discussed in depth in the (unextended) QLF benchmarking literature, the benchmarks are implicitiy assumed to be more accurate, in the mean square error sense, than the corresponding totals of the original series. This is apparent in that the revised (benchmarked) series are forced to agree with the benchmark values. In certain instances, this is clearly the correct approach. For example, when the subannual series is based on sample survey data and the benchmarks are based on a census of the same sample frame (as is the case for the EIA residential natural gas series), it is clear that the benchmark values will be of far greater accuracy. In other cases, the benchmark values may be based on a census of an appropriate frame, while the subannual series is derived from an analysis of related data which are not sample based. The latter situation describes EIA coal production series, where weekly production figures are based on an analysis of rail shipments, production data, and model results, while quarterly and annual benchmarks are derived from censuses of appropriately defined frames. Again, it is reasonable to believe that the benchmark values are of greater accuracy, since they represent more direct measurements of the desired information.

When both a benchmark and its corresponding sum of subannuals are subject to quantifiable error (e.g., unbiased with known covariance structure), it may be possible to derive a benchmark with smaller variance by choosing an optimal (i.e., minimum variance) linear combination of the two estimates. This new benchmark can be used with the penalty function of choice to derive the adjustment series $x-z$. Note that this approach is only to be used for QLF 
benchmarking, since the assumptions of the model-based and GLS techniques imply that the benchmarks are independent of the series $z$. 


\subsection{REVIEW OF EIA APPLICATIONS AND PROCEDURES}

\subsection{RESIDENTIAL NATURAL GAS DELIVERIES APPLICATION}

Background

Among the data reported on a monthly basis in the Natural Gas Monthly (NGM) are estimates of natural gas deliveries (in millions of cubic feet) to residential customers, by state. Geographical coverage includes the fifty states and the District of Columbia. The estimates are based on data reported on the Form EIA-857 "Monthly Report of Natural Gas Purchases and Deliveries to Consumers." Since the latter is a sample survey, annual census data from the Form EIA-176 "Annual Report of Natural and Supplemental Gas Supply and Disposition" are used to inflate the sample data to represent population volumes for the entire sample frame. Initial estimates are based on data obtained from the Form EIA-176 for a prior year, while final estimates are adjusted to reflect data obtained for the reported year.

\section{Benchmarking}

For a given state and year, the sample of companies reporting on the Form EIA-857 remains fixed throughout the calendar year. The initial volume estimate for month $m$ is given by:

$$
V I_{m}=y_{m} .\left(Y_{p} . / Y_{p}{ }_{p}\right)
$$

where $y_{\mathrm{m}} .=$ the sum of the volumes for month $m$ reported on the Form EIA-857

$Y_{p}$. = the sum of annual volumes for all companies in the state in the prior year as reported on the Form EIA-176

$Y^{\prime} p .=$ the sum of the prior year annual volumes for all companies in the current sample, based on the Form EIA-176.

Note that the expression for $V_{m}$ is equivalent to expression (4), Appendix C, of the April, 1989 Natural Gas Monthly. 
After the annual data for a given year reported on the Form EIA-176 have been prepared for publication in the Natural Gas Annual (NGA), monthly volume estimates for that year are revised to reflect the annual data for the same year. The revised volume estimate for month $m$ is given by:

$$
\begin{aligned}
& V R_{m}=Y g .\left(V I_{m} / \Sigma_{j} V_{j}\right) \\
& =Y_{g} \cdot\left[y_{m} .\left(Y_{p .} / Y^{\prime}{ }_{p .}\right)\right] /\left[\Sigma_{j} y_{j} .\left(Y_{p} . / Y^{\prime} p_{.}\right)\right] \\
& =Y_{g} \cdot\left(y_{m} . / \Sigma_{j} y_{j} .\right) \\
& \left.=y_{m} .\left(Y_{g} . Y^{\prime} g_{.}\right) \text {(using } \Sigma_{j} y_{j}=Y^{\prime} g_{.}\right)
\end{aligned}
$$

where $Y_{g} .=$ the sum of annual volumes for all companies in the state in the given year as reported on the Form EIA-176

$Y^{\prime} g .=$ the sum of the given year annual volumes for all companies in the current sample, based on the Form EIA-176.

Note that $V_{R_{m}}$ is equivalent to (6), Appendix C, of the Apri1, 1989 Natural Gas Monthly

The revised estimates $V R_{m}$ represent improvements over the initial estimates $V I_{m}$ in two ways. First, the revised estimates are ratio estimates based on annual data for the given year, rather than a prior year. Second, the revised estimates sum to the annual total for the given year:

$$
\begin{aligned}
\Sigma_{m} V_{R_{m}} & =\Sigma_{m} y_{m}\left(Y_{g .} / Y_{g}^{\prime} g\right) \\
& =Y_{g}^{\prime} g\left(Y_{g .} / Y^{\prime} g .\right) \\
& =Y_{g} .
\end{aligned}
$$

Because of the second improvement, the revised estimates can be formally described as (single year) benchmarked versions of the initial estimates. Recall from Section 1.1 that QLF revisions are determined by minimizing a penalty function involving the initial and revised estimates, subject to the benchmarking constraint. It is easily shown that the current revision technique is equivalent to QLF benchmarking using any of the penalty functions corresponding to trend revision, logarithmic trend revision, or first 
proportional difference revision. For example, trend revision requires minimization of the penalty function $p_{0}=\Sigma_{m}\left(V I_{m} / V I_{m+1}-V R_{m} / V R_{m}+1\right)^{2}$. But $V_{m} / V I_{m+1}=y_{m} / y_{m+1},=V R_{m} / V R_{m+1}$, so that $p_{0}=0$.

\section{Consideration of Benchmarking Alternatives}

As shown above, the current revision scheme is equivalent to single year QLF benchmarking of the initial estimates $V_{m}$. Alternatives one might consider include multiple-year QLF benchmarking, single or multiple-year model-based benchmarking, or single or multiple-year GLS benchmarking.

A basic assumption shared by both the model-based and GLS approaches is that the initial estimates $z=\left(V I_{1}, V_{2}, \ldots, V_{12}\right)$ must be unbiased (Sections 1.2 and 1.3). Because they are inflated based on data from a prior year, the initial estimates, $V I_{m}$, for a given year will be biased whenever the total volumes for the two years do not agree. As a result, neither mode1based nor GLS benchmarking of the $V I_{m}$ is recommended. Although no specific assumptions are violated, multiple-year QLF benchmarking is rejected as well, since the correction of model inadequacies (due, in this case, to inflation by the total for the wrong year) is not the proper role of benchmarking. Consistent with this point of view, it preferable to think of the $V_{m}$ simply as more appropriate "initial" estimators (which happen to satisfy the benchmark constraints) rather than as benchmarked versions of the $V I_{m}$.

\section{Final Recommendations}

The current method for benchmarking of the residential natural gas delivery series is the most appropriate method, given the ratio estimation scheme used to produce the initial estimates $V I_{m}$. No change is reconmended.

The geographic level and time-scale of the current method for benchmarking of the residential natural gas delivery series are appropriate. Furthermore, because of the bias inherent in the initial estimates $V_{m}$, multiple-year benchmarking is not appropriate. No change is recommended.

The benchmarking of residential natural gas delivery series should be revisited if the method of producing the initial estimates $V I_{m}$ is changed. In particular, if sample-based techniques (e.g., weighting by inverse selection 
probabilities, etc.) are used to inflate sample totals to the $\mathrm{VI}_{\mathrm{m}}$, rather than the ratio $Y_{p .} / Y^{\prime} p_{\text {. }}$, other benchmarking techniques should be considered.

Example

If, as suggested previously, we ignore the $V I_{m}$ and consider the $V R_{m}$ to be the "initial" estimators, it is of interest to consider whether some form of benchmarking might be applied to the $V R_{m}$. Since the benchmark constraints $\Sigma_{m} V R_{m}=Y_{g}$. are already satisfied, the purpose of such an exercise would be to determine whether some benefit might be derived from a more careful modeling of the covariance structures of the sampling error e or the observed series $z=\left(V R_{1}, V_{2}, \ldots\right)$. The following example is provided for that purpose.

In the example we investigate the feasibility of benchmarking a four year series (1984-1987) of monthly estimates (VR $R_{m}$ of natural gas deliveries to residential consumers (NGM, Table 22) in the state of Virginia. As noted above, the benchmark constraints have already been met as a result of the definition of $V R_{m}$; thus, our goal is to incorporate additional information regarding the sampling error $e$ and the observed series $z=\left(V R_{1}, V R_{2}, \ldots\right.$, VR48) into the benchmarking process. It must be emphasized that this example is provided for the purpose of illustration only, since numerous assumptions have been made on the basis of minimal supporting data. Benchmarking of the residential natural gas delivery series in this manner is not recommended at this time.

The Hillmer-Trabelsi (1987) model-based approach depends upon obtaining a suitable ARMA model for $e$. In the case of the EIA's residential natural gas series, monthly estimates for a given year are based on a single sample of establishments, while the samples for different years are drawn independently. Thus monthly sampling errors within a calendar year are correlated, while errors between years are uncorrelated, resulting in an error structure not well represented by an ARMA model. This makes the GLS approach the method of choice for adjustment of $\mathbf{z}$.

We first consider modeling of the series $z$. As is apparent in Figure 2, the series is highly seasonal. Upon removing a deterministic seasonal 


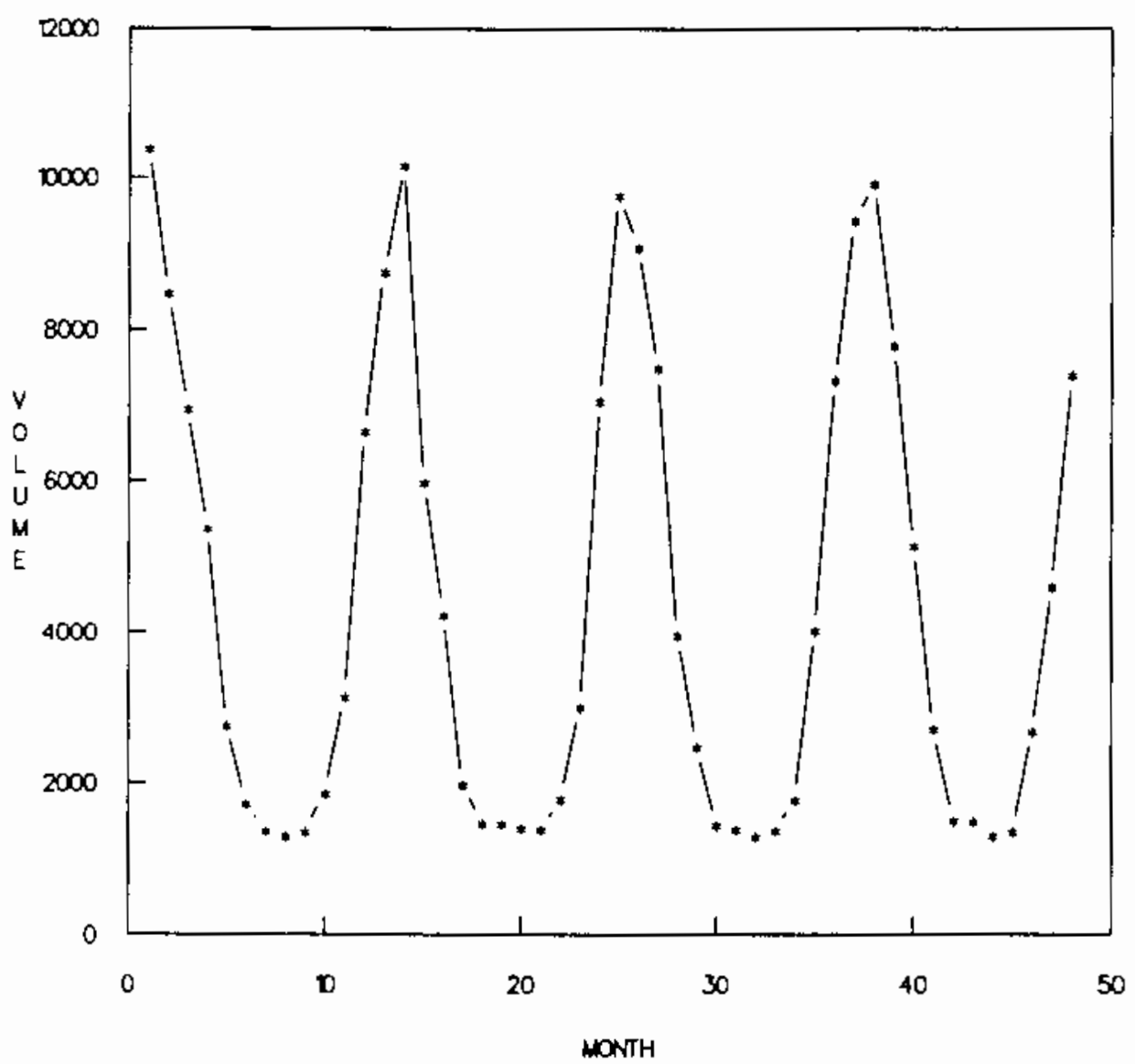

FIGURE 2. Virginia Residential Natural Gas Deliveries, 1984-1987 (Million Cubic Feet)

component $s$ found by regressing $z$ on the independent variables $\cos (t x / 6)$, $\sin (t \pi / 6), \cos (t \pi / 3)$, and $\sin (t \pi / 3)$, the first 46 autocorrelations and partial autocorrelations were found to be nonsignificant; hence, it was assumed that $z=s+v+e$, (equations (i) and (iv), Section 1.3) where $v$ and $e$ are independent, error terms and $V_{\mathbf{z}}=\operatorname{Cov}(v+e)$ is diagonal. Comparison of the variation of particular calendar months across years reveals much greater variation for the colder months (when deliveries are greatest) than for the warmer months (when deliveries are smallest). These observations were summarized by taking the covariance matrix $V_{z}$ of $z$ to be diagonal with ith diagonal element equal to the estimated variance across years for the calendar month corresponding to the observation $z_{j}$. (The estimated variances, January 
through December, were: $4.549 \mathrm{e} 5,6.034 \mathrm{e} 5,6.377 \mathrm{e} 5,4.726 \mathrm{e} 5,1.279 \mathrm{e} 5,1.684 \mathrm{e} 4$, $3.292 \mathrm{e} 3,2.812 \mathrm{e} 3,9.492 \mathrm{e} 1,1.863 \mathrm{e} 5,5.715 \mathrm{e} 5,1.139 \mathrm{e} 5$.

An approximate form for the covariance structure for e can be inferred from the sampling scheme. Since an independent sample of establishments is generated on a yearly basis, with the same establishments being used to generate monthly results within a calendar year, we can assume that $e_{j}$ and $e_{k}$ are highly correlated if $j$ and $k$ correspond to months within the same calendar year, and uncorrelated otherwise. Unfortunately, little data currently exist for estimating this covariance structure, as standard errors for the monthly estimates have only been reported for February and March of 1989 (NGM, March 1989 and April 1989, Table C-2). Comparing the standard deviations across years to the standard errors for the months of February and March yielded a ratio of approximately 3.5:1. In order to continue the analysis, it was assumed that the same ratio is maintained for other months and that the correlation between months within a calendar year is 0.8 . With the assumptions made previously, this allowed specification of $V_{e}$. The matrix $V_{v}$ was obtained by subtraction; i.e., $V_{v}=V_{z}-V_{e}$. Further assuming $V_{u}=0$ and $V_{w}=0$, the adjusted series $x$ was computed using the two step process described in Section 1.3; i.e.,

$$
\begin{aligned}
n_{0}^{*} & =V\left(n_{0}^{\star}\right)\left[V_{e}^{-1} z+V_{v}-1 s\right] \\
x & =n_{0}^{*}+V\left(n_{0}^{\star}\right) B^{\prime}\left[B V\left(n_{0}^{\star}\right) B^{\prime}\right]-1\left[y-B n_{0}^{\star}\right],
\end{aligned}
$$

where $V\left(n_{0}^{*}\right)=\left[V_{e}-1+V_{v}-1\right]$. As indicated in Figure 3 , the relative adjustments $\left(x_{t}-z_{t}\right) / z_{t}$ to the $V R_{m}$ data series were small. Reducing the correlation between months within a calendar year to 0.5 gave similar results.

\subsection{COAL PRODUCTION APPLICATION}

\section{Background}

The EIA estimates weekly, monthly, quarterly, and annual coal production at the national, regional and state levels. Initial estimates of national weekly coal production are based on weekly data collected by the Association 


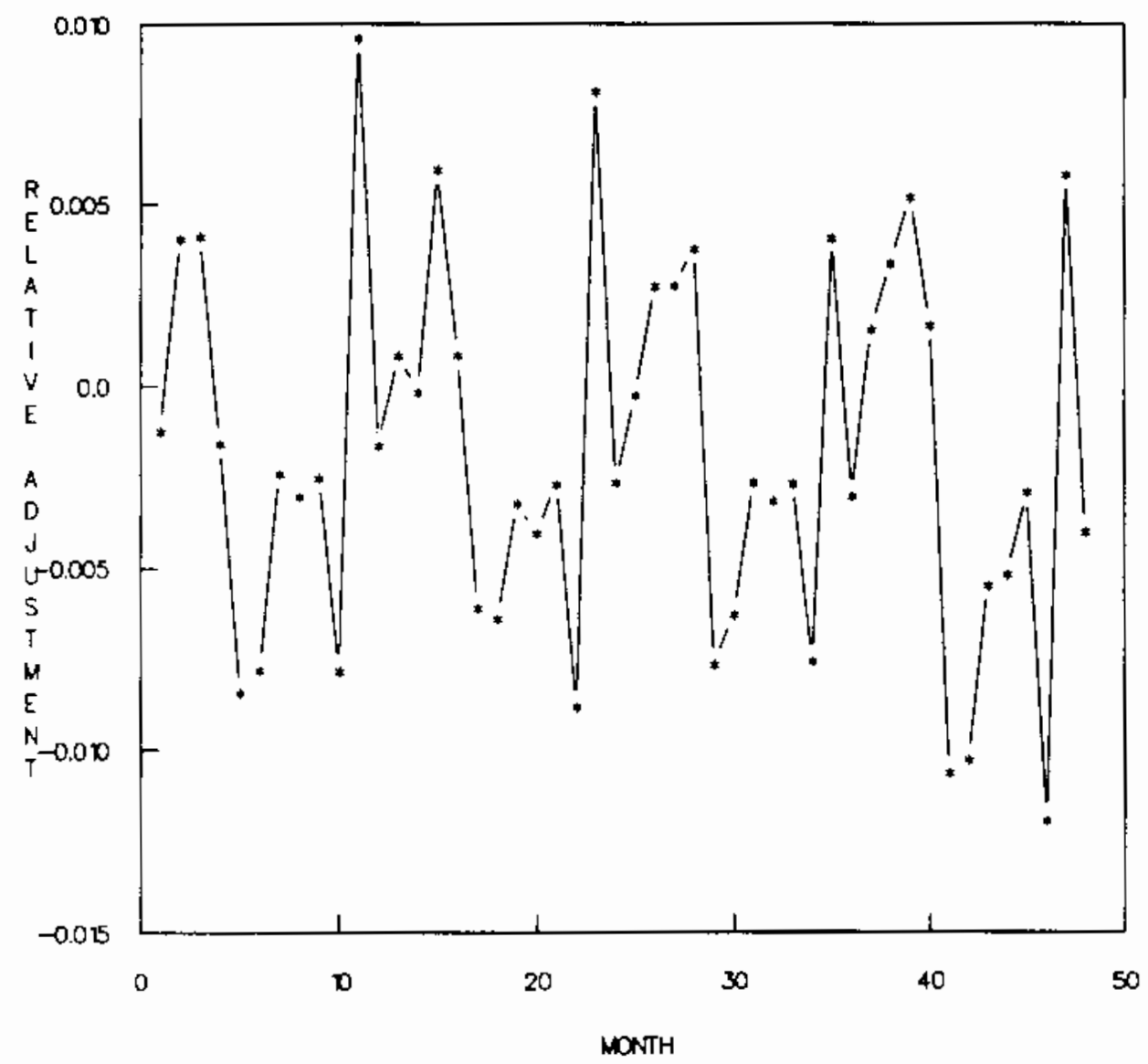

FIGURE 3. Relative Adjustments $(x-z) / z$ in Virginia Residential Natural Gas Series, 1984-1987 (GLS Technique).

of American Railroads (AAR). These data are adjusted to represent total production for all states for the week and allocated among the states based on related data. Initial monthly estimates are derived from the weekly data. A preliminary national estimate of quarterly production is obtained from the Form EIA-6, and preliminary quarterly estimates of regional and state production are derived from the Form EIA-6 and other data. Finally, annual estimates are derived from a variety of sources, including reports collected by various governmental agencies. Additional details on data collection and summarization are given in the Quarterly Coal Report and Balthasar (1988). 


\section{Benchmarking}

Initial estimates of monthly production by state are obtained by summing the weekly estimates and allocating partial weeks according to predetermined percentages which are assumed to account for differences in weekdays, weekends, and holidays (Balthasar, 1988); thus, if we denote the initial weekly estimate for week $w_{\text {by }} P I_{W}$, the initial monthly estimate $P_{m}$ for month m can be written:

$$
P I_{m}=\Sigma_{W} \beta_{W} P I_{W}
$$

where $\quad \mathrm{PI}_{\mathrm{m}}=$ the initial production estimate for month $\mathrm{m}$

$$
\beta_{\mathrm{w}}=\text { the proportion of production for week } w \text { allocated to month } \mathrm{m}
$$

$\Sigma_{w}=$ summation over the weeks wholely or partially in month $m$.

The initial quarterly estimate for quarter $q$ is simply

$$
P I_{q}=\Sigma_{m} P I_{m} \text {. }
$$

where $\quad P_{\mathrm{q}}=$ the initial production estimate for quarter $\mathrm{q}$

$\Sigma_{m}=$ summation over the months in quarter $q$.

The initial weekly and monthly estimates are revised quarterly when quarterly production data, $P_{q}$, become available. (Initial estimates for the fourth quarter may not undergo a first revision, depending on the size of the difference between the initial estimates and the fourth quarter data.) These revisions take the form of proportional adjustments which force the initial weekly and monthly estimates to sum to the quarterly production figures. Based on the written descriptions in Balthasar (1988), the first weekly revisions can be described mathematically as follows:

$$
P R I_{w}=P I_{w} \cdot \Sigma_{q}\left\{a_{w}(q) P q / P I_{q}\right\}
$$

where $\quad P R I_{W}=$ the first revised production estimate for week $w$ 


$$
\begin{aligned}
a_{w}(q)= & \text { the proportion of production for week } w \text { assigned to } \\
& \text { quarter } q \\
\Sigma_{q}= & \text { summation over the quarters wholely or partially } \\
& \text { containing week } w .
\end{aligned}
$$

The first revision for month m can be described by:

$$
P R I_{m}=P I_{m} \cdot P_{q}(m) / P I_{q}(m)
$$

where $\quad P R 1_{m}=$ the first revised estimate for month $m$

$$
q(m)=\text { the quarter containing month } m \text {. }
$$

When finalized annual production figures are available, a revision of the quarterly figures is performed, as is a second revision of the weekly and monthly data. If $P y$ denotes the final annual production figure, the revised figure for quarter $q^{\prime}$ can be written:

$$
P R_{q^{\prime}}=P_{q^{\prime}} \cdot P_{y} /\left(\Sigma_{q} P_{q}\right)
$$

The second revisions for the monthly estimates are:

$$
P R 2_{m}=P R 1_{m} \cdot P R_{q(m)} / P q(m)
$$

where $\quad P R 2 m=$ the second revision of the monthly production for month $m$ $q(m)=$ the quarter containing month $\mathrm{m}$.

Finally, the second revisions for the weekly estimates are:

$$
P 2_{w}=P R 1_{w} \cdot \Sigma_{q}\left\{a_{w}(q) P R_{q} / P q\right\}
$$

Although the initial weekly and monthly estimates are not sample-based, but are instead derived from a variety of production-related data, each level of benchmark is based on a census of an appropriate frame. For example, quarterly figures are obtained from a survey of U.S. producers and/or distributors that own or purchase more that 50,000 short tons of coal 
annually; annual figures are based on all coal mining companies which own a mining operation that produces, processes, or prepares 10,000 or more short tons of coal annually in the United States. While the error inherent in the initial (weekly and monthly) estimates is difficult to quantify, the benchmark series are likely to be more accurate (in the mean square error sense), since they represent a more direct measurement of the desired information. Comparing the two senchmark periods (quarterly and annual), it is likely that the annual benchmarks are less prone to error, since they are based on a frame which includes additional small producers.

Consideration of Benchmarking Alternatives

The lack of information on the statistical properties of the initial weekly and monthly coal production estimates makes the application of modelbased or related GLS benchmarking somewhat problematic. On the other hand, because these estimates are not derived from a sequence of independent samples (as are the natural gas series), it may be more reasonable to assume an underlying autoregressive error structure (although some systematic biases may also exist). These considerations suggest that the QLF approach be employed in any benchmarking of coal series.

From a mean square error standpoint, we would expect the final yearly benchmark, $P_{y}$, to be more accurate than the sum of the quarterly benchmarks, $\Sigma_{q} P_{q}$. since the former is based on producers of 10,000 or more short tons of coal per year, while the latter is based on producers of 50,000 or more short tons per year. We would also expect the quarterly estimates, $\mathrm{Pq}_{\mathrm{q}}$, to be more accurate than the corresponding sums of the initial weeklies, $\mathrm{PI}_{q}$, since the latter are not sample-based.

Based on the remarks in the preceding paragraph, it is recommended that the final annual benchmarking of coal series proceed in stages. In the first stage, the quarterly benchmarks should be adjusted to the more accurate annual benchmarks. This will result in improved quarterly benchmarks, which can then be used to adjust the initial weekly and monthly estimates.

A choice between the various forms of QLF benchmarking can be made by examination of a multiple-year series of initial estimates. Recall 
(Section 1.2) that if significant seasonality is found, and the variation for a particular subannual period (e.g., month or week) across years appears to be an increasing function of level, Cholette's form of relative revision is indicated. Otherwise, Cholette's version of first difference revision is recommended. For the coal application, the monthly aggregations of the "Estimated Weekly Data" series (i.e., the initial monthly series, PIm) from the Coal Common Data File were examined for the State of Indiana for the period from January, 1986 through December, 1988. Monthly data were studied in order to capture seasonality while avoiding the greater instability of the weekly data. It was found that seasonal variation was not dramatic, with the maximum monthly production values only 20-50 percent greater than minimum monthly production values during the years examined. More important, no correlation was found between the average production level for a given calendar month and the variation of values for that month across years. As a result of these observations, Cholette's version of first difference revision is indicated.

\section{Final Recommendations}

Consistent with the remarks in the preceding paragraph, Cholette's first difference technique (Section 1.1) is recommended for the benchmarking of coal production series.

The current practice of benchmarking coal production series on the state level or higher is appropriate and should be continued. The current timeperiods for revision (i.e., quarterly revisions as the quarterly benchmark data become available, followed by an annual revision when the annual figures are finalized) are also appropriate.

Care should be exercised in replacing the current proportional benchmarking with the recommended QLF first difference technique. Under the recommended technique, each revision is made to the initial weekly and monthly estimates, not to the most recent revisions of those estimates (as is the case under the current technique). 
For many calendar years, the first and/or final weeks are in fact only partial weeks, as was the case in 1987. The QLF techniques fail to account for this fact, and assign a "full" adjustment to these weeks. This may result in over-adjustments for these partial weeks, but is easily rectified by adding an additional quarter of data to each end of the year, as in the following procedure:

1. When the benchmarks for the first quarter become available, the initial weekly and monthly estimates corresponding to the last quarter of the prior year and the first quarter of the current year are simultaneously adjusted to agree with the quarterly benchmarks. If the first week of the current quarter is a partial week, only the correct portion of the total weekly adjustment is made in reporting the adjusted result for that partial week (Balthasar 1988). If the last week of the first quarter is a partial week, no adjustment is reported at this time.

2. When the benchmarks for the second quarter become available, the initial weekly and monthly estimates corresponding to the last quarter of the prior year and the first two quarters of the current year are simultaneously adjusted to agree with the quarterly benchmarks. If the first week of the current quarter is a partial week, only the correct portion of the total weekly adjustment is made in reporting the adjusted result for that partial week. If the last week of the second quarter is a partial week, no adjustment is reported at this time. If the last week of the first quarter was a partial week, the adjusted result can be reported at this time.

3. When the benchmarks for the third quarter become available, the initial weekly and monthly estimates corresponding to the last quarter of the prior year and the first three quarters of the current year are simultaneously adjusted to agree with the quarterly benchmarks. If the first week of the third quarter is a partial week, only the correct portion of the total weekly adjustment is made in reporting the adjusted result for that partial week. If the last week of the third quarter is a partial week, no adjustment is reported at this time. If the last week of the second quarter was a partial week, the adjusted result can be reported at this time.

4. When the benchmarks for the fourth quarter become available, the initial weekly and monthly estimates corresponding to the last quarter of the prior year and the first four quarters of the current year are simultaneously adjusted to agree with the quarterly benchmarks. If the first week of the fourth quarter is a partial week, only the correct portion of the total weekly adjustment is made in reporting the adjusted result for that partial week. If the last week of the fourth quarter is a partial week, no adjustment is reported at this time. If the last week of the third quarter was a partial week, the adjusted result can be reported at this time. 
5. When the final annual results become available,

a) the quarterly benchmarks are simultaneously adjusted to agree with the final annual results, as in the example below, and

b) the initial weekly and monthly estimates for the last quarter of the prior year, all quarters of the current year, and the first quarter of the succeeding year are simultaneously adjusted to agree with the adjusted quarterly figures for the prior and current years, and the unadjusted quarterly benchmarks for the first quarter of the succeeding year. This scheme determines adjustments corresponding to the entire calendar weeks associated with the first and last weeks of the current year. If the first and/or final week is a partial week, the Balthasar (1988) factor can be computed to determine the proportion of the adjustment applicable to the current year.

The benchmarking of coal production series should be reviewed if the method of producing the initial estimates $\mathrm{PI}_{W}$ is changed or if future coal production shows greater monthly variation. In the latter case, Cholette's first proportional difference technique should be considered if calendar months exhibiting high average levels of production show greater variability than calendar months exhibiting lower average levels of production.

Example

To illustrate the application of QLF 1DA benchmarking to coal data, 1987 initial weekly coal production estimates for the State of Indiana are benchmarked to the more accurate quarterly and annual results (Step 5, above). The revisions obtained are then compared to revisions resulting from the current proportional methods.

All data except the quarteriy benchmarks $P_{q}$ were obtained from the coal Common Data file and were expressed to the nearest short ton. The only readily available source for the quarterly benchmarks was the QCR, in which the data were rounded to the nearest thousand short tons.

The first step in the benchmarking process is to adjust the initial quarterly benchmarks to agree with the final annual total. The results of applying first difference adjustment (1DA) are illustrated in Table 1. These results are obtained using the formulas for the implementation of the Cholette approach from Section 1.1. According to that notation, the series to be benchmarked is $z=$ column 2 of Table 1 . The benchmark is the final annual total $y=34,208,204$. The matrix $B^{\prime}=\left[\begin{array}{llll}1 & 1 & 1 & 1\end{array}\right]$, so that the annual 
TABLE 1. Adjustment of Initial Quarterly Benchmarks to Annual Total (1987 Indiana Coal Production in Short Tons)

\begin{tabular}{lccc}
$\begin{array}{c}\text { Initial Quarterly } \\
\text { Totals } \\
\left(\mathrm{PI}_{\mathrm{q}}\right)\end{array}$ & $\begin{array}{c}\text { Quarterly } \\
\text { Benchmarks } \\
\left(\approx \mathrm{Pq}_{\mathrm{q}}\right)\end{array}$ & $\begin{array}{c}\text { Adjusted Quarterly } \\
\text { Benchmarks (1DA) } \\
(\approx \mathrm{PRq})\end{array}$ \\
\hline 1087 & $7,561,567$ & $7,980,000$ & $8,028,551$ \\
2087 & $7,576,940$ & $8,289,000$ & $8,337,551$ \\
3087 & $8,087,818$ & $8,806,000$ & $8,854,551$ \\
4087 & $9,326,894$ & $8,939,000$ & $8,987,551$ \\
TOTALS & $32,553,219$ & $34,014,000$ & $34,208,204$ \\
* From Common Coal Data File & \\
** From Quarterly Coal Report &
\end{tabular}

discrepancy is $r=y-B^{\prime} z=34,208,204-34,014,000=194,204$. The matrix $A$, which describes the penalty function, is given by $A=D^{\prime} D$, where

$$
\mathbf{D}=\left|\begin{array}{rrrr}
-1 & 1 & 0 & 0^{-} \\
0 & -1 & 1 & 0 \\
0 & 0 & -1 & 1
\end{array}\right| \text {. }
$$

We now obtain the matrix $C$ as the upper right $4 \times 1$ submatrix of

$$
H=\left|\begin{array}{ll}
-A & B^{-} \\
B^{\prime} & 0
\end{array}\right|^{-1}\left[\left.\begin{array}{cc}
-A & 0^{-} \\
B^{\prime} & I
\end{array}\right|^{-}\right. \text {. }
$$

and find that $C^{\prime}=\left[\begin{array}{llll}0.25 & 0.25 & 0.25 & 0.25\end{array}\right]$; thus, the adjusted quarterly values are $x=z+C r=\left[\begin{array}{lll}8028551833755188545518987551\end{array}\right]^{\prime}=$ Column 3, Table 1 .

The second step in the benchmarking process is to benchmark the initial weekly and monthly estimates $\left(\mathrm{PI}_{\mathbf{W}}\right.$ and $\left.\mathrm{PI}_{\mathbf{m}}\right)$ to the revised quarterly sums. Because weeks are often broken between quarters, while months are not, 
benchmarking of the $\mathrm{PI}_{\mathrm{w}}$ is the more difficult task and will therefore be illustrated. To apply the techniques of Section 1.1, we take $z$ to be the initial weekly estimates and $y$ to be Column 3 of Table 1. A complication arises here in that quarters are comprised of varying numbers of weeks and weeks may split between quarters. This is dealt with in the definition of the constraint matrix $B$. To carry out first difference adjustment, we take A79x79 $=0^{\prime} 0$, where $078 \times 79$ is defined as in Section 1.1, page 3, but with the first row removed. The constraint matrix $B 79 \times 6$ is of the form

$$
B=\left[\begin{array}{llllll}
j_{1} & 0 & 0 & 0 & 0 & 0 \\
0 & j 2 & 0 & 0 & 0 & 0 \\
0 & 0 & j 3 & 0 & 0 & 0 \\
0 & 0 & 0 & j 4 & 0 & 0 \\
0 & 0 & 0 & 0 & j 5 & 0 \\
0 & 0 & 0 & 0 & 0 & j_{6}
\end{array}\right] \text {. }
$$

where the $j_{i}$ are column vectors which define the accumulation of weeks into quarters. For example, the last quarter of 1986 included wednesday through Saturday of the fortieth week of the year and all of weeks forty-one through fifty-two. The fifty-third, and final, week of the year was split between 1986 and 1987. According to the current algorithm for splitting a week (Balthasar 1988), 60.0\% of that week's production was allocated to the last quarter of 1986 , and the remaining $40.0 \%$ was allocated to the first quarter of 1987. Thus $j_{1}$ is a column vector of length 14 with 1 's in the first thirteen positions and 0.60 in the fourteenth position. (The first and last weeks of a multi-quarter benchmarked period each receive a weight of 1 if they represent positive production figures, regardless of their respective lengths.) The vector $j 2$ begins with a 0.4 in the row 14 , column 2 position and ends with a 0.364 (its share of the fourteenth week of 1987) in the row 27, column 2 position; the remaining positions hold 1's. 
Having defined $A$ and $B$, the matrix $C$ is defined using Cholette's technique (Section 1.1, page 7). The adjustments $x-z$ to the weekly series are $\mathbf{C r}$, where $r=\left[\begin{array}{lll}476749 & 466984760611766733-339343-693401\end{array}\right] '$. The first and last entries of $r$ represent actual quarterly production minus estimated quarterly production for 4086 and 1088, respectively, as reported in the Coal Common Data File. The center four entries are from Column 3 minus Column 1, Table 1.

Figure 4 compares the adjustments $x-z$ for Cholette's QLF first difference and first proportional difference techniques. Note that the techniques give similar results, except in the final quarter of the year. Figure 5 compares the relative adjustments $(x-z) / z$ for the techniques. Strict adherence to proportional benchmarking dictates that the plot for the current technique remain constant within a given quarter (except for weeks split between quarters). Figure 5 indicates this is not the case in the final months of the year, suggesting that non-benchmarking adjustments (e.g., revisions from data suppliers) were also made during that period. 


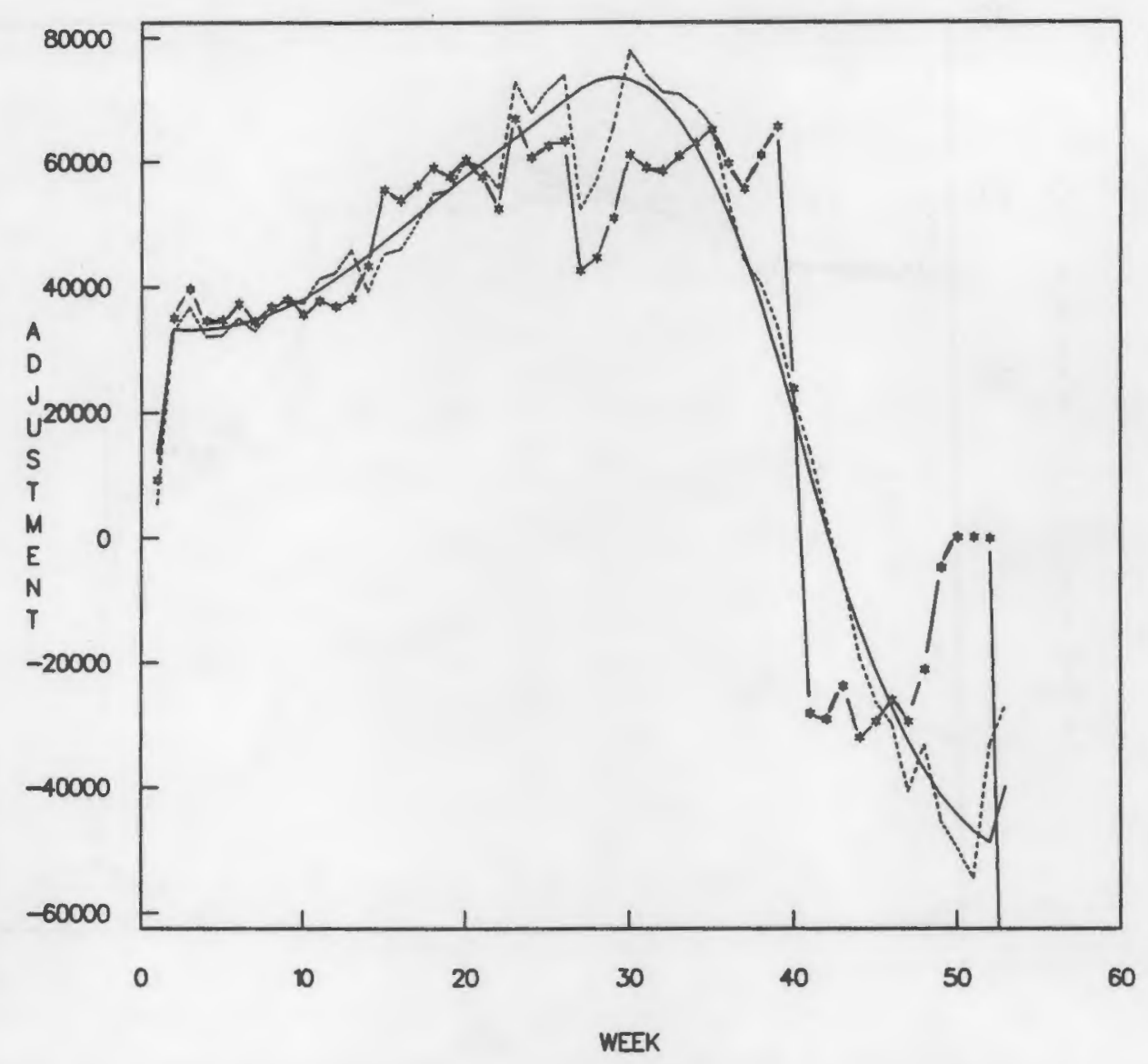

FIGURE 4. Additive Adjustments $x-z$ to 1987 Indiana Coal Production (Short Tons). Current technique $\left(-^{*_{-} *_{-} *_{-}}\right)$, Cholette's first difference technique ( first proportional difference technique $(\ldots ..) \cdot$. 


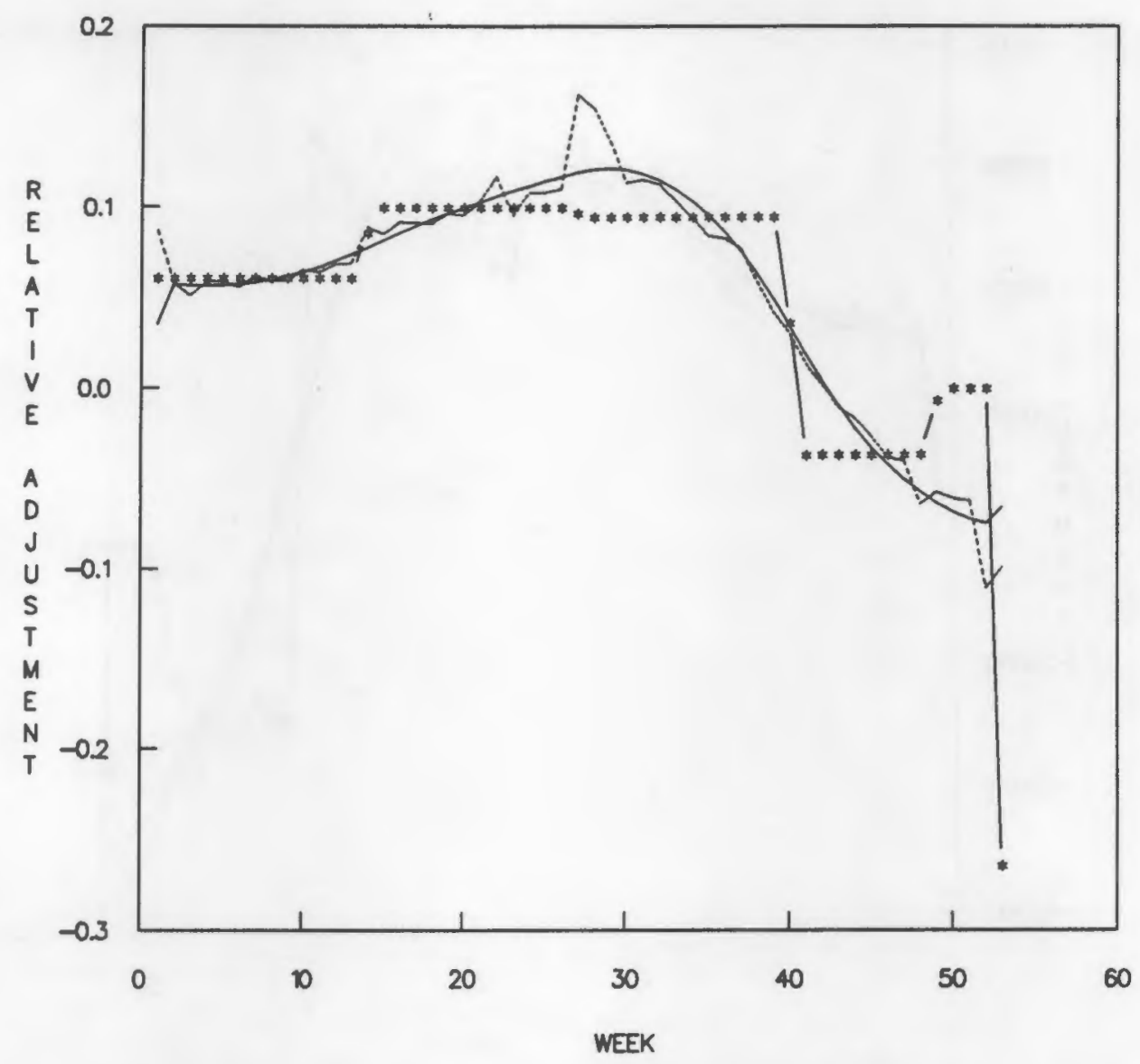

FIGURE 5. Relative Adjustments $(x-z) / z$ to 1987 Indiana Coal Production. Current technique $\left(-^{*}-\star_{-}-_{-}\right)$, Cholette's first difference technique (- - , and Cholette's first proportional difference technique $(\ldots . \cdots)$. 


\subsection{CITED BIBLIOGRAPHY}

Balthasar, N.C. 1988. "Methodology to Estimate Weekly Coal Production." Agenda Item 2, ASA Conmittee on Energy Statistics.

Bozik, J.E. and M. C. Otto. 1988. Benchmarking: Evaluating Methods That Preserve Month-to-Month Changes. Statistical Research Division Report No. CENSUS/SRD/RR-88/07, Bureau of the Census.

Cholette, P.A. 1979. "Adjustment Methods of Sub-Annual Series to Yearly Benchmarks." Proceedings of the Computer Science 12th Annual Symposium on the Interface, ed. J.F. Gentleman, 358-360.

Cholette, P.A. 1978. A Comparison and Assessment of Various Adjustment Methods of Sub-Annual Series to Yearly Benchmarks. Seasonal Adjustment and Time Series Analysis Staff Report, Statistics Canada.

Cholette, P.A. 1984. "Adjusting Sub-Annual Series to Yearly Benchmarks." Survey Methodology 10:35-49.

Cholette, P.A. and E.B. Dagum. 1989. Socio-Economic Time Series Data: A Unified Approach. Working Paper No. TSRA-89-006E, Time Series Research and Analysis Division, Methodology Branch, Statistics Canada.

Cleveland, W.P. and G.C. Tiao. 1976. "Decomposition of Seasonal Time Series: A Model for the Census X-11 Program." JASA 71:581-587.

Denton, F.T. 1971. "Adjustment of Monthly or Quarterly Series to Annual Totals: An Approach Based on Quadratic Minimization." JASA 64:99-102.

Fernandez, R.B. 1981. "A Methodological Note on the Estimation of Time Series." Review of Economics and Statistics 63:471-476.

Helfand, S.O., N.J. Monsour, and M.L. Trager. 1977. "Historical Revision of Current Business Survey Estimates." Proceedings of the Business and Economic Statistics Section. American Statistical Association. Alexandria, VA.

Hillmer, S.C. and A. Trabelsi. 1987. "Benchmarking of Economic Time Series." JASA $84(400): 1064-1071$.

Hillmer, S.C. and G.C. Tiao. 1982. "An ARIMA-Model-Based Approach to Seasonal Adjustment." JASA 77:63-70.

Laniel, N. 1986. Adjustment of Economic Production Sub-Annual Series to Corresponding Annual Series. Working Paper No. BSMD-86-006E (preliminary version), Business Survey Methods Division, Methodology Branch, Statistics Canada. 
Monsour, N.J. and M.L. Trager. 1979. "Revision and Benchmarking of Business

Time Series." Proceedings of the Business and Economic Statistics Section, pp. 333-337. American Statistical Association, Alexandria, VA.

Scott, A.J. and T.M.F. Smith. 1974. "Analysis of Repeated Surveys Using Time Series Methods." JASA 69:674-678.

Scott, A.J., T.M.F. Smith, and R.G. Jones. (1977). "The Application of Time Series Methods to the Analysis of Repeated Surveys." International

Statistical Review 45:13-28.

Wolter, K.M. 1985. Introduction to Variance Estimation. Springer-Verlag, New York. 


\subsection{CITED EIA DATA SOURCES}

Annual Report of Natural and Supplemental Gas Supply and Disposition, Form EIA-176.

Coal Common Data File.

Monthly Report of Natural Gas Purchases and Deliveries to Consumers, Form EIA-857.

Natural Gas Annual (DOE/EIA-0131).

Natural Gas Monthly (DOE/EIA-0130).

Quarterly Coal Report (DOE/EIA-0121). 


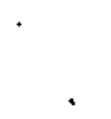

-

,

- 


\subsection{SUPPLEMENTARY BIBLIOGRAPHY}

Be11, W. 1984. "Signal Extraction for Nonstationary Time Series." Annals of Statistics 12:646-664.

Box, G.E.P., S.C. Hillmer, and G.C. Tiao. 1978. "Analysis and Modelling of Seasonal Time Series." Seasonal Analysis of Economic Time Series, ed. A. Zellner, pp. 309-334. US Department of Commerce, Washington, DC.

Cholette, P.A. 1988. Concepts, Definitions and Principles of Benchmarking and Interpolation of Time Series. Working Paper No. TSRA-87-014E (preliminary version), Time Series Research and Analysis Division, Methodology Branch, Statistics Canada.

Cholette, P.A. 1985. Estimating Sub-Annual Series from Growth Rates and Annual Benchmarks. Working Paper No. TSRA-85-018E (preliminary version), Time Series Research and Analysis Division, Methodology Branch, Statistic Canada.

Cholette, P.A. 1984. "Linking Heterogeneous Segments of Seasonal Time Series." Proceedings of the Business and Economic Statistics Section, pp. 178-183. American Statistical Association, Alexandria, VA.

Cholette, P.A. and J. Higginson. 1987. A Note on Aggregating Data Referring to Different Financial Years. Working Paper No. TRSA-87-015E, Time Series Research and Analysis Division, Methodology Branch, Statistics Canada.

Chow, G.C. and A. Lin. 1971. "Best Linear Unbiased Interpolation, Distribution and Extrapolation of Time Series by Related Series." Review of Economics and Statistics 53:372-375.

Friedman, M. 1962. "The Interpolation of Time Series by Related Series." JASA $57: 729-757$.

Litterman, R.B. 1983. "A Random Walk, Markov Model for the Distribution of Time Series." Journal of Business \& Economic Statistics 1:169-173. 


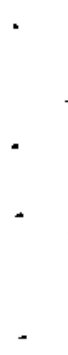




\section{DISTRIBUTION}

No. of

Copjes

OFFSITE

M. Welch

Energy Information

Administration

1000 Independence Ave. SW

Washington, DC 20585

2 DOE Office of Scientific and

Technical Information

\author{
Y. Bishop \\ Energy Information \\ Administration \\ 1000 Independence Ave., SW \\ Washington, DC 20585 \\ S. Freedman \\ Energy Information \\ Administration \\ 1000 Independence Ave., SW \\ Washington, DC 20585 \\ D. Hale \\ Energy Information \\ Administration \\ 1000 Independence Ave., SW \\ Washington, DC 20585 \\ N. Kirkendall \\ Energy Information \\ Administration \\ 1000 Independence Ave., SW \\ Washington, DC 20585
}

No. of

Copies

ONSITE

16 Pacific Northwest Laboratory

R. L. Cheatham

A. R. Olsen

R. G. Pratt

T. J. Secrest

W. G. Stillwell

M. A. Williamson (5)

Publishing Coordination

Technical Report Files 

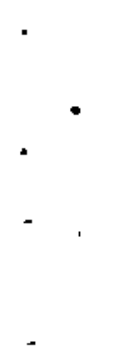